\title{
METODOLOGIA dE ENSAIO DE FLEXÃO VERTICAL PARA AVALIAÇÃo DE EIXO VEICULAR UTILIZADO EM SUSPENSÃO PNEUMÁTICA DE IMPLEMENTOS RODOVIÁRIOS
}

\author{
Sergio Francisco Dela Antônio ${ }^{1}$ e Luiz Eduardo Lopes ${ }^{1}$ \\ ${ }^{1}$ Instituto de Pesquisas Tecnológicas do Estado de São Paulo S/A- IPT \\ E-mails: $\underline{\text { sfda@ipt.br e luizel@ipt.br }}$
}

\section{RESUMO}

Os eixos utilizados em implementos rodoviários, reboques e semirreboques, a partir de julho/2015 serão objetos de certificação. O IPT possui laboratório acreditado para realização dos ensaios dos eixos conforme a Norma "ABNT 10961:2009 - Implementos Rodoviários Caminhão, caminhão trator, ônibus, reboque e semirreboque - Eixo veicular - Requisitos e métodos de ensaios". A metodologia de ensaio constante nesta norma foi baseada em normas anteriores e em nada se alterou em termos técnicos nas ultimas revisões. As metodologias das normas anteriores foram adotadas na época em que praticamente $100 \%$ das suspensões dos veículos eram com feixes de molas, não levando em consideração as novas tecnologias que utilizam suspensões pneumáticas. Este trabalho apresenta uma comparação de métodos do ensaio de flexão vertical, para eixos utilizados em suspensões pneumáticas, sendo um dos métodos conforme a norma NBR 10961 e outro desenvolvido pelo IPT baseado na condição real de utilização. Para as duas metodologias foram feitas simulações por elementos finitos e ensaios experimentais de laboratório em um mesmo modelo de eixo, o qual foi instrumentado com extensômetros elétricos para monitoração de tensões. Os níveis de tensões no eixo ensaiado conforme a aplicação real foi até $25 \%$ maior do que as ocorridas no eixo ensaiado conforme a norma NBR 10961.

\section{INTRODUÇÃO}

Os eixos veiculares traseiros utilizados em caminhões e implementos rodoviários como reboques e semirreboques, a partir de 2015 serão objetos de certificação compulsória no Brasil. Cada modelo de eixo deverá ter todo o processo de fabricação auditado e avaliado periodicamente. Esta avaliação da auditoria será baseada em um Regulamento Técnico da Qualidade aprovado e publicado pelos órgãos gestores deste tipo de certificação no Brasil.

Parte importante deste regulamento técnico são os ensaios aos quais o produto deve atender. As metodologias de ensaios adotadas no regulamento atual foram baseadas na Norma "ABNT 10961:2009 - Implementos Rodoviários - Caminhão, caminhão trator, ônibus, reboque e semirreboque - Eixo veicular - Requisitos e métodos de ensaios" [1]. Por sua vez, as metodologias de ensaios da Norma mencionada foram baseadas em normas antigas que em nada se alteraram tecnicamente nas ultimas revisões. Essas metodologias foram criadas quando os caminhões e implementos rodoviários tinham capacidade de carga menor e possuíam somente suspensões com feixes de molas. 
Atualmente muitos veículos possuem eixos com suspensão pneumática que é considerada uma evolução tecnológica com relação aos sistemas de suspensão com feixes de molas. As montagens dos eixos nestes dois tipos de suspensão são diferentes. Na suspensão com feixes de molas as longarinas do veículo são apoiadas nas extremidades dos feixes que por sua vez são fixados sobre os apoios soldados diretamente sobre o eixo, conforme Figura 5 . Na suspensão pneumática as longarinas são apoiadas sobre os braços da suspensão que por sua vez são soldados no eixo; um lado dos braços é um ponto fixo em relação à longarina e no outro lado é colocada uma bolsa de ar que funciona como o elemento mola, conforme Figura 3.

$\mathrm{Na}$ certificação do eixo os ensaios devem ser realizados conforme o regulamento atual. Para o ensaio de flexão vertical que simula a carga dinâmica do veículo sobre o eixo, os eixos utilizados em suspensões pneumáticas devem ser modificados e ensaiados como se fossem utilizados em suspensões com feixes de molas. Para isso o eixo da suspensão pneumática deve ser alterado para ficar parecido com um eixo de suspensão com feixes de molas. No lugar dos braços da suspensão soldados no eixo para a reação das cargas devem ser soldados os suportes utilizados para fixação dos feixes de molas, onde serão aplicadas as forças no ensaio.

Ensaiar um eixo utilizado em suspensão pneumática como se fosse um eixo utilizado em suspensão com feixes de molas não representa as condições reais de uso do eixo e tampouco as condições impostas pelo processo de fabricação. Estas alterações nos eixos podem gerar esforços diferentes dos que acontecem na aplicação real e comprometer a análise da vida em fadiga. Firat [2] propõe a simulação numérica de teste de fadiga por flexão de 4 pontos de um eixo para feixes de molas utilizando a metodologia de análise integrada de fadiga e elementos finitos. No trabalho fica evidente a importância na vida em fadiga dos concentradores de tensão introduzidos pelo processo de fabricação. Wang, X. et al [3] propõem a simulação numérica do ensaio de fadiga de flexão vertical da estrutura de um eixo automotivo traseiro para estimar, na fase de projeto, se o eixo passaria os testes e quais alteração seriam necessárias para atingir tal objetivo. Além disso, estudam as relações entre os resultados dos testes e aquele colhidos no campo de provas, onde os projetos são finalmente validados. Lee, Yuejun E. [4] analisa a correlação entre o projeto e os resultados dos testes de flexão vertical de eixos automotivos. A adaptação de deslocamento e deformação para metas de correlação mostra resultados que podem ser altamente não lineares devido aos erros experimentais e ruído. A confiança em se achar uma solução global ótima é altamente limitada sem uma ferramenta de busca que considere o espaço completo de projeto. Propõe um novo algoritmo de otimização, baseado na técnica de exploração de projeto, para a busca da solução ótima.

O objetivo deste trabalho foi avaliar a relação entre os esforços ocorridos no eixo veicular utilizado em suspensão pneumática quando o mesmo é submetido à duas metodologias de ensaio de flexão vertical diferentes, porém com o mesmo carregamento. Uma das metodologias foi baseada na norma NBR 10961 e outra foi desenvolvida pelo IPT onde foi definida uma montagem que simulou a aplicação real no veículo. Atualmente o IPT possui uma bancada para o ensaio conforme a norma NBR 10961.

\section{DESENVOLVIMENTO DA METODOLOGIA}

As ações realizadas para desenvolvimento da metodologia de ensaio foram: 
a) Desenvolvimento de uma nova bancada de ensaio para simulação da montagem real do eixo, com suspensão pneumática.

b) Modelagem e simulação por elementos finitos dos dois eixos para os carregamentos nos ensaios conforme a metodologia normalizada e a metodologia em desenvolvimento, com o levantamento dos pontos críticos de esforços nos eixos.

c) Instrumentação de dois eixos, um com a fabricação original dos componentes para instalação em suspensão pneumática e outro de mesma origem, porém modificado para suspensão com feixes de molas.

d) Realização de ensaios estáticos com sistema de aquisição de dados para leitura dos esforços nos eixos para as duas metodologias;

e) Análise dos resultados obtidos dos esforços nos eixos para ambas as metodologias.

\subsection{Eixo para Suspensão Pneumática}

O eixo objeto deste trabalho é apresentado nas Figuras 1 e 2. O eixo possui as seguintes especificações técnicas:

- Tipo: Usinado, tubular com $146 \mathrm{~mm}$ de diâmetro externo, $12 \mathrm{~mm}$ de parede e $2.218 \mathrm{~mm}$ de comprimento total. O lado fixo do braço da suspensão é montado com uma bucha polimérica que permite um pequeno movimento em todas as direções.

- Carga nominal: 11 ton $(107,9 \mathrm{kN})$

- Utilização: eixo traseiro de caminhões com suspensão pneumática;

- Distancia entre braços da suspensão: 931 mm;

- Bitola: $1860 \mathrm{~mm}$;

- Material: FB-70

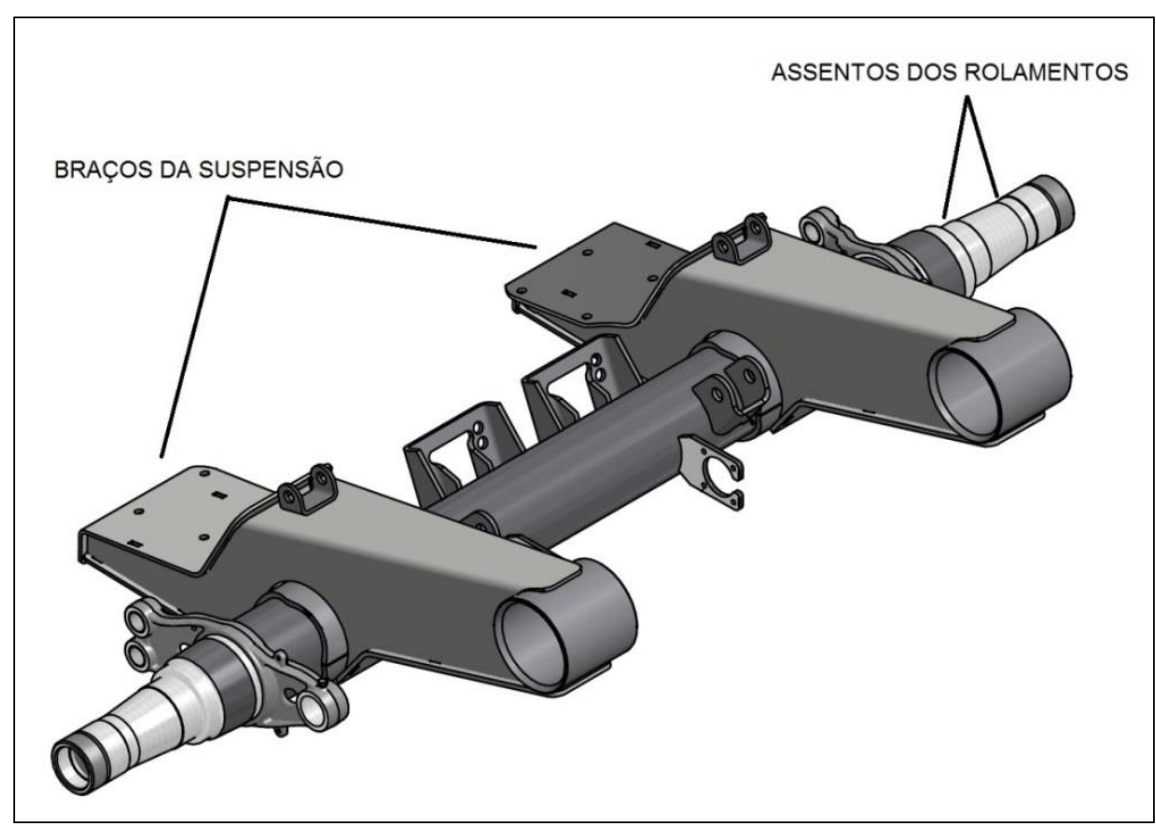

Figura 1 - Eixo para Suspensão Pneumática (perspectiva) 


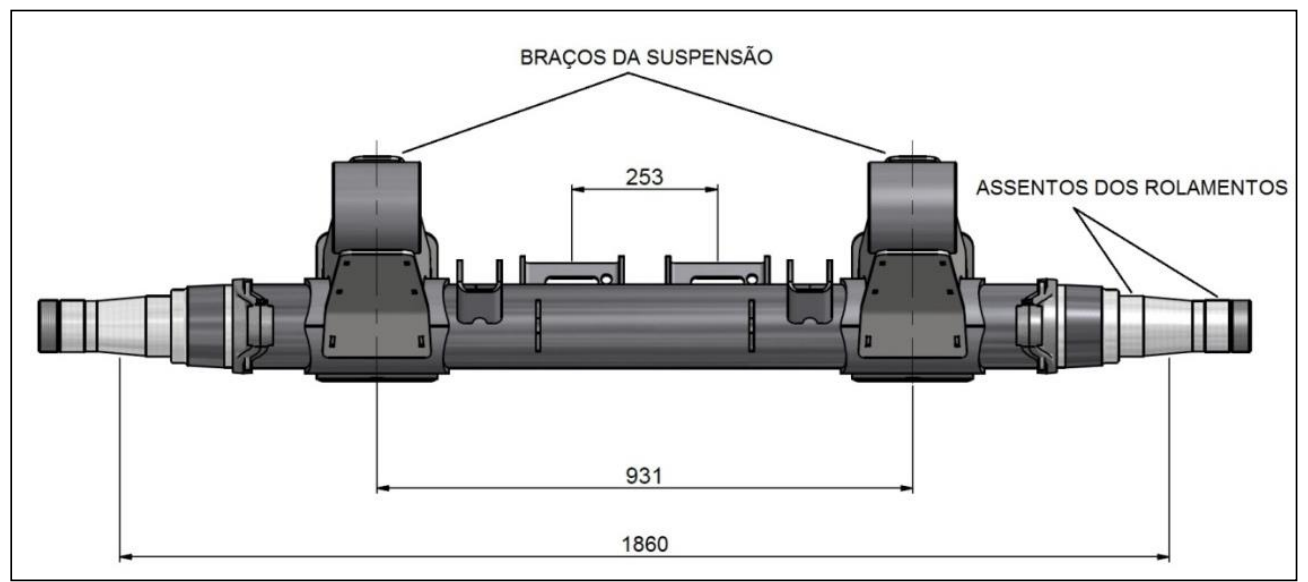

Figura 2 - Eixo para Suspensão Pneumática (vista de frente)

O esquema de montagem do eixo na suspensão pneumática é apresentado na Figura 3. As cotas correspondem ao veículo carregado.

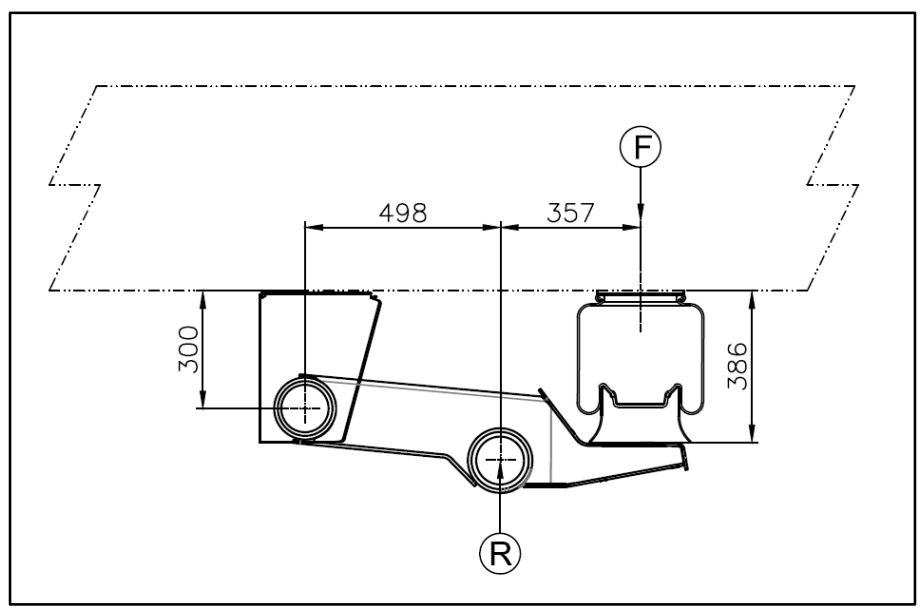

Figura 3 - Esquema de montagem da suspensão pneumática

\subsection{Bancada de ensaio conforme a norma NBR 10961.}

A bancada de ensaio de flexão vertical conforme a norma NBR 10961 é apresentada na Figura 4. Basicamente a bancada é constituída de um quadro de reação autoportante, com 2 atuadores servo controlados, para aplicação da força sobre os assentos dos feixes de molas. Em cada ponta do eixo é montada uma bucha de aço sobre as sedes dos rolamentos onde se dará a reação das forças. As buchas são apoiadas sobre roletes com $100 \mathrm{~mm}$ de diâmetro que são apoiados sobre uma base rígida.

Para os ensaios de certificação a força aplicada no ensaio é dinâmica com frequência entre 0,5 e $10 \mathrm{~Hz}$, variando de $5 \mathrm{kN}$ a duas vezes a carga nominal do eixo. O eixo deve resistir a 300.000 ciclos sem apresentar fratura e ser ensaiado com todos os componentes que gerem calor, soldados ou fixados por outro meio. 


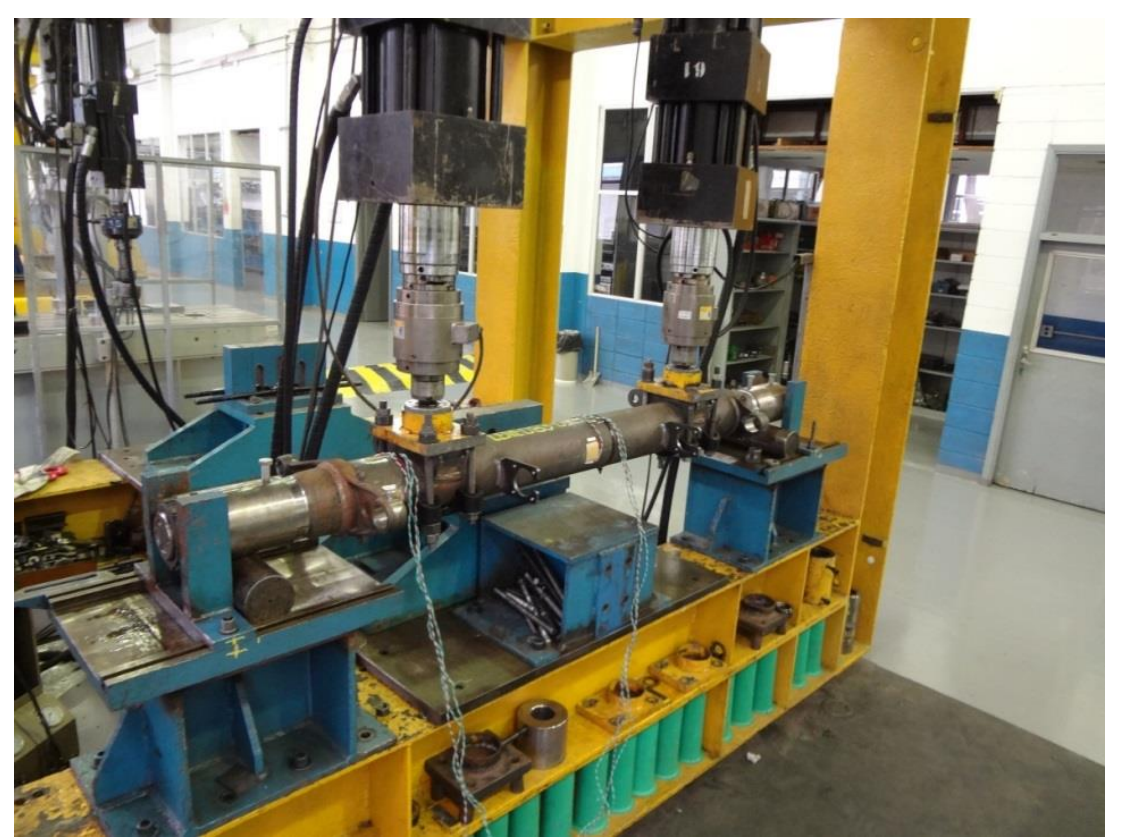

Figura 4 - Bancada de ensaio de flexão vertical conforme NBR 10961

Para que o eixo de suspensão pneumática possa ser ensaiado conforme a NBR 10961 deve-se alterar sua configuração, fixando no lugar dos braços da suspensão os apoios dos feixes de molas, conforme Figura 5.

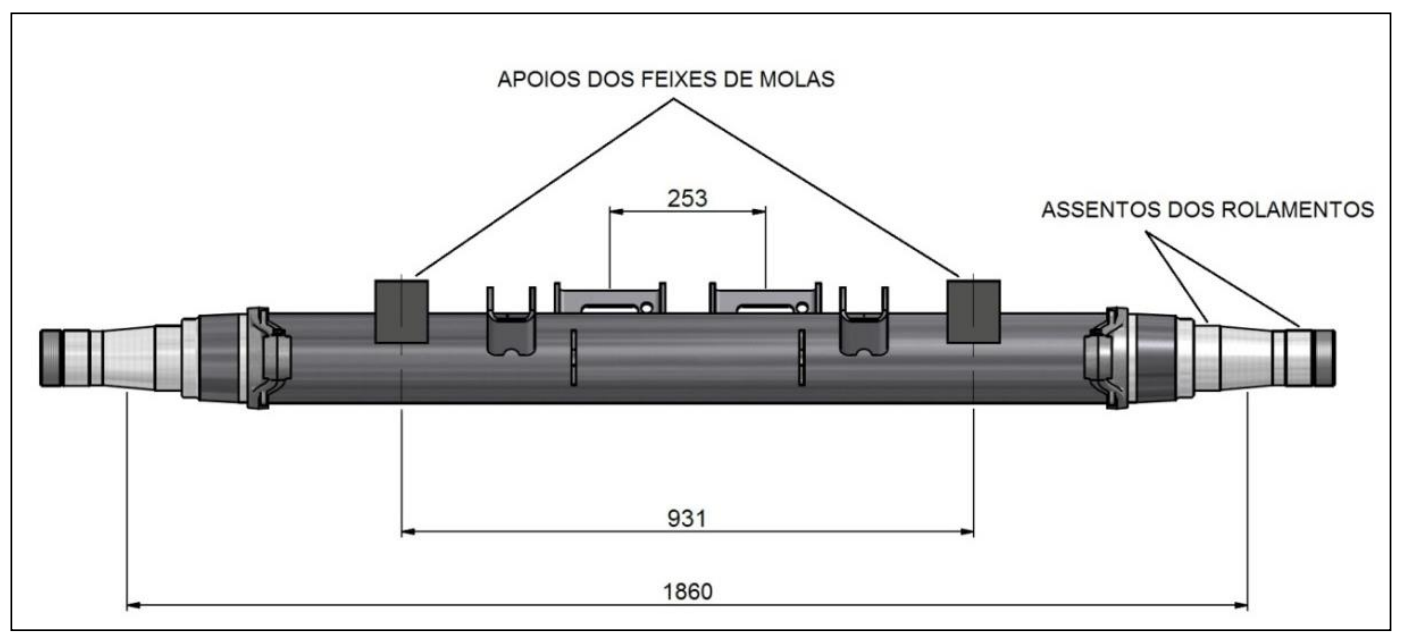

Figura 5 - Eixo de suspensão pneumática modificado para ensaio conforme NBR 10961

2.3. Concepção da nova bancada de ensaio para simulação do eixo no veículo com suspensão pneumática

A nova bancada de ensaio, apresentada na Figura 6, foi concebida e desenvolvida pelo IPT tendo como referência as cotas e desenhos de instalação no caminhão do eixo objeto do trabalho. A bancada é constituída de um quadro de reação, autoportante, dois atuadores servo controlados, para aplicação das forças e o dispositivo de fixação do eixo. As forças são aplicadas no lado do braço da suspensão onde é montada a bolsa de ar. O outro lado do braço é montado em um suporte rígido que permite o pivotamento no sentido longitudinal do veículo. 


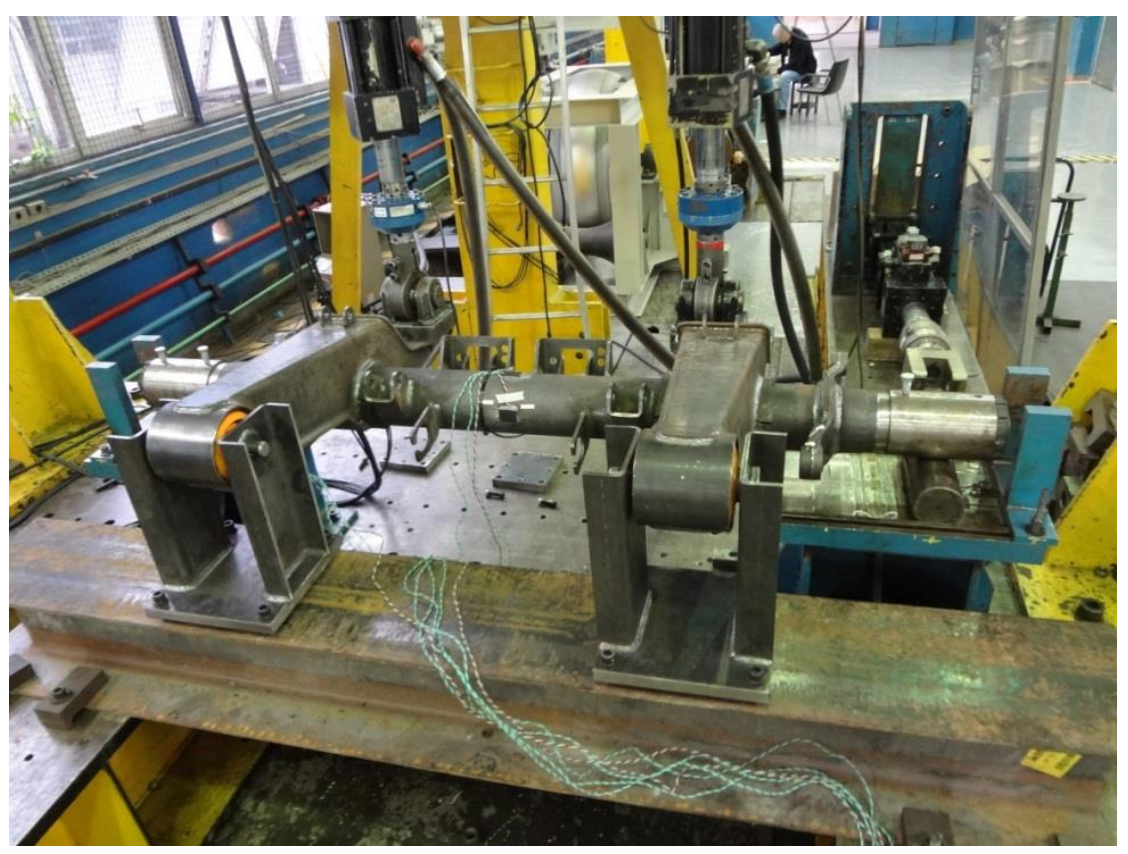

Figura 6 - Bancada de ensaio de flexão vertical - suspensão pneumática

\subsection{Modelamento Tridimensional}

Baseados nos desenhos de fabricação foram feitos dois modelos tridimensionais do eixo. Um dos modelos do eixo com os componentes originais, inclusive com as buchas poliméricas, para instalação na suspensão pneumática, conforme Figura 7, e outro modelo com suportes de feixes de molas substituindo o braço da suspensão, conforme Figura 8.

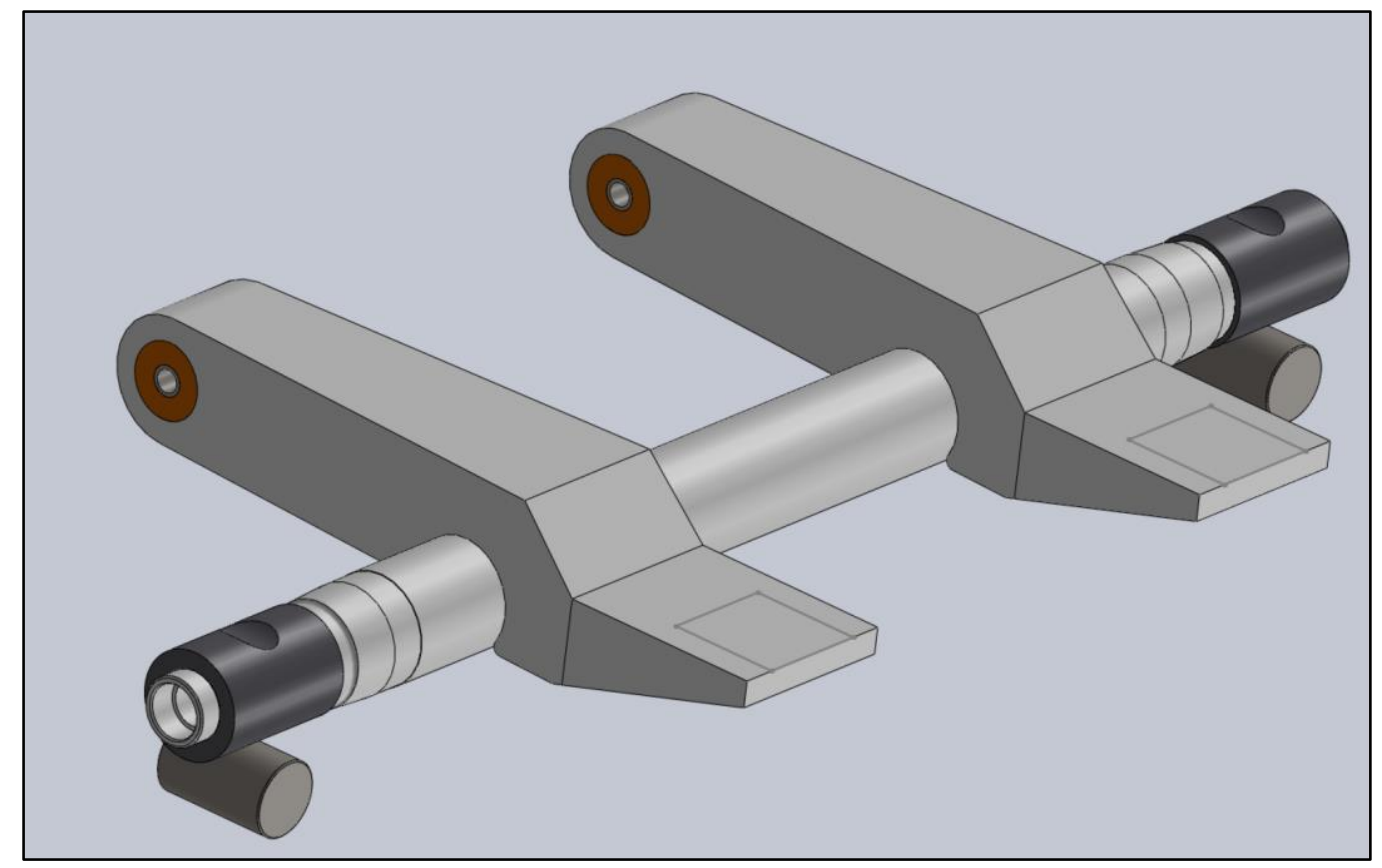

Figura 7 - Modelo tridimensional do eixo para suspensão pneumática 


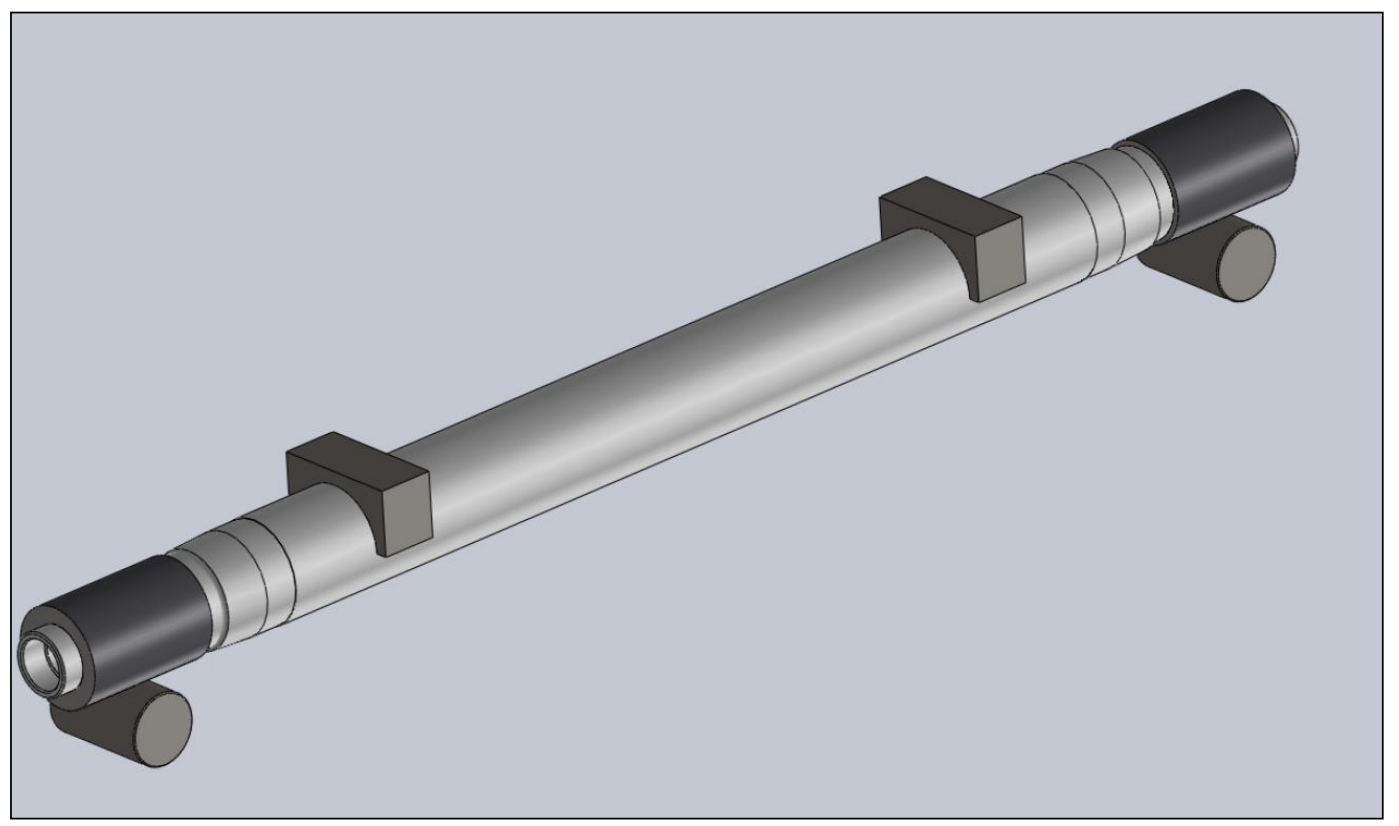

Figura 8 - Modelo tridimensional do eixo modificado com suportes de feixes de molas

\subsection{Simulação por Elementos Finitos}

Nas simulações por elementos finitos (FEA), para os dois ensaios/eixos, foram utilizados os seguintes parâmetros:

- Força aplicada no eixo: 215,6 kN (2 vezes a carga nominal, 107,9 kN em cada apoio)

- Análise: estática

- Tipo de malha: malha sólida

Os valores de deformações e deslocamentos, resultantes das simulações, são apresentados nas Figuras 9, 10, 11 e 12.

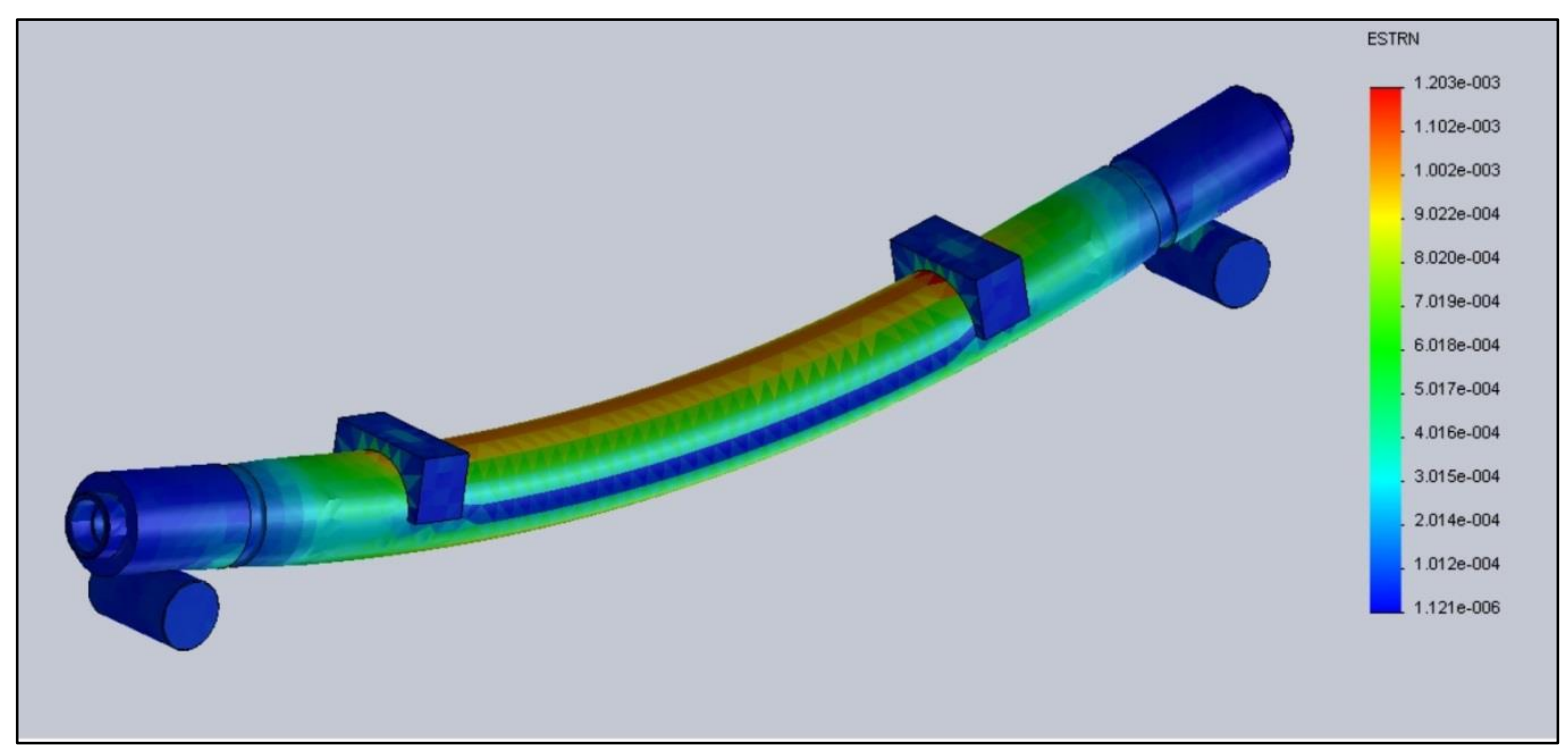

Figura 9 - Simulação das deformações, escala de distorção de 20 vezes 


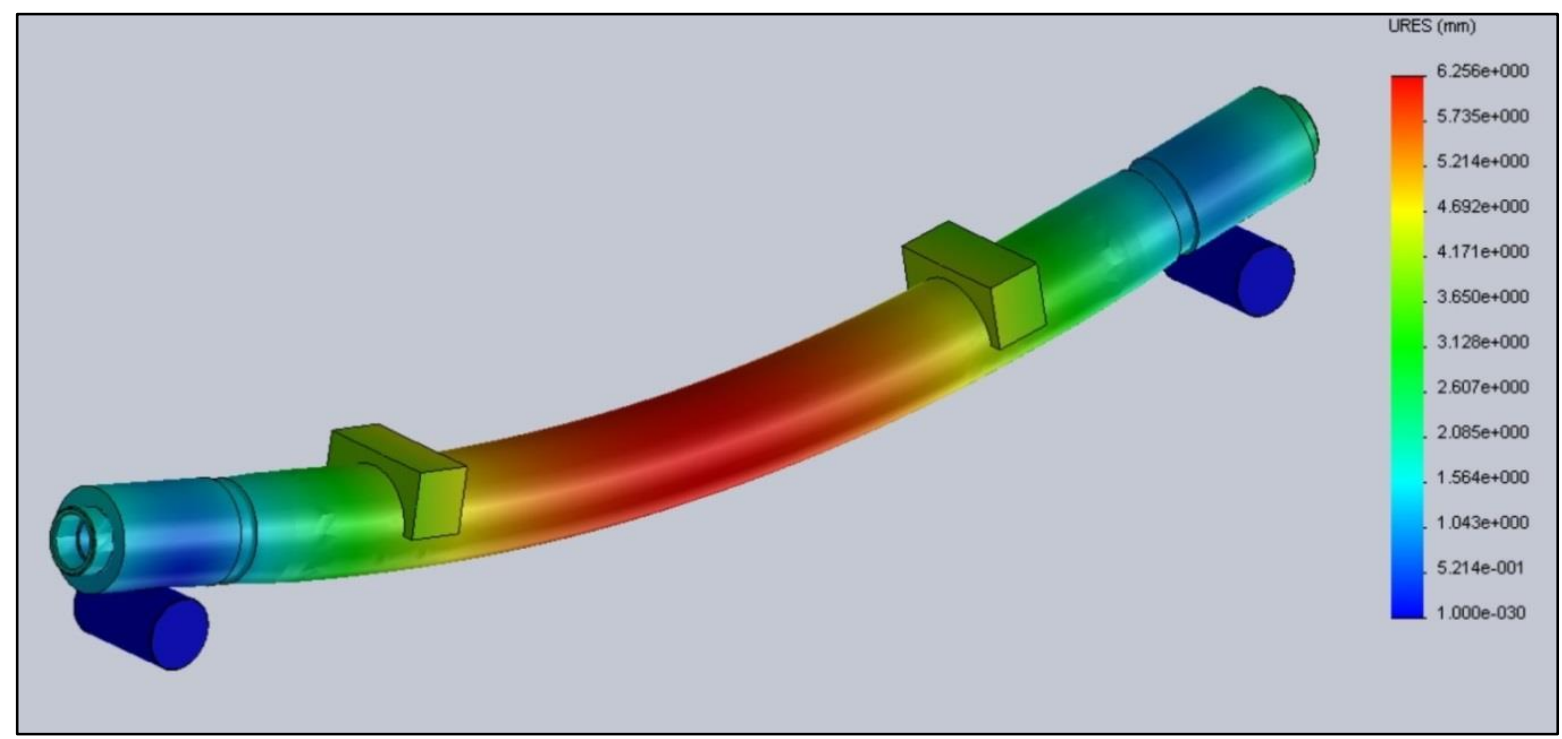

Figura 10 - Simulação dos deslocamentos, escala de distorção de 20 vezes

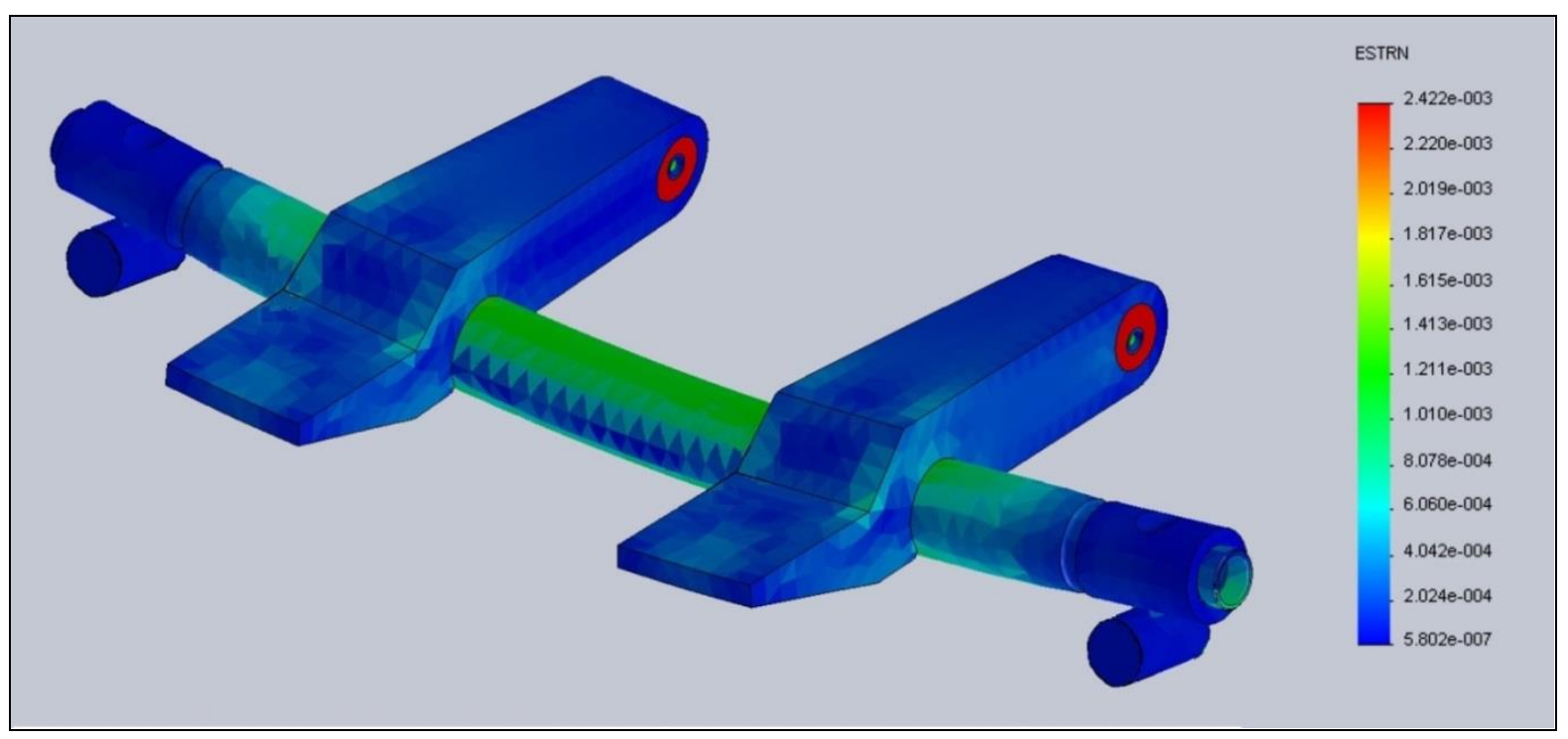

Figura 11 - Simulação das deformações, escala de distorção de 10 vezes

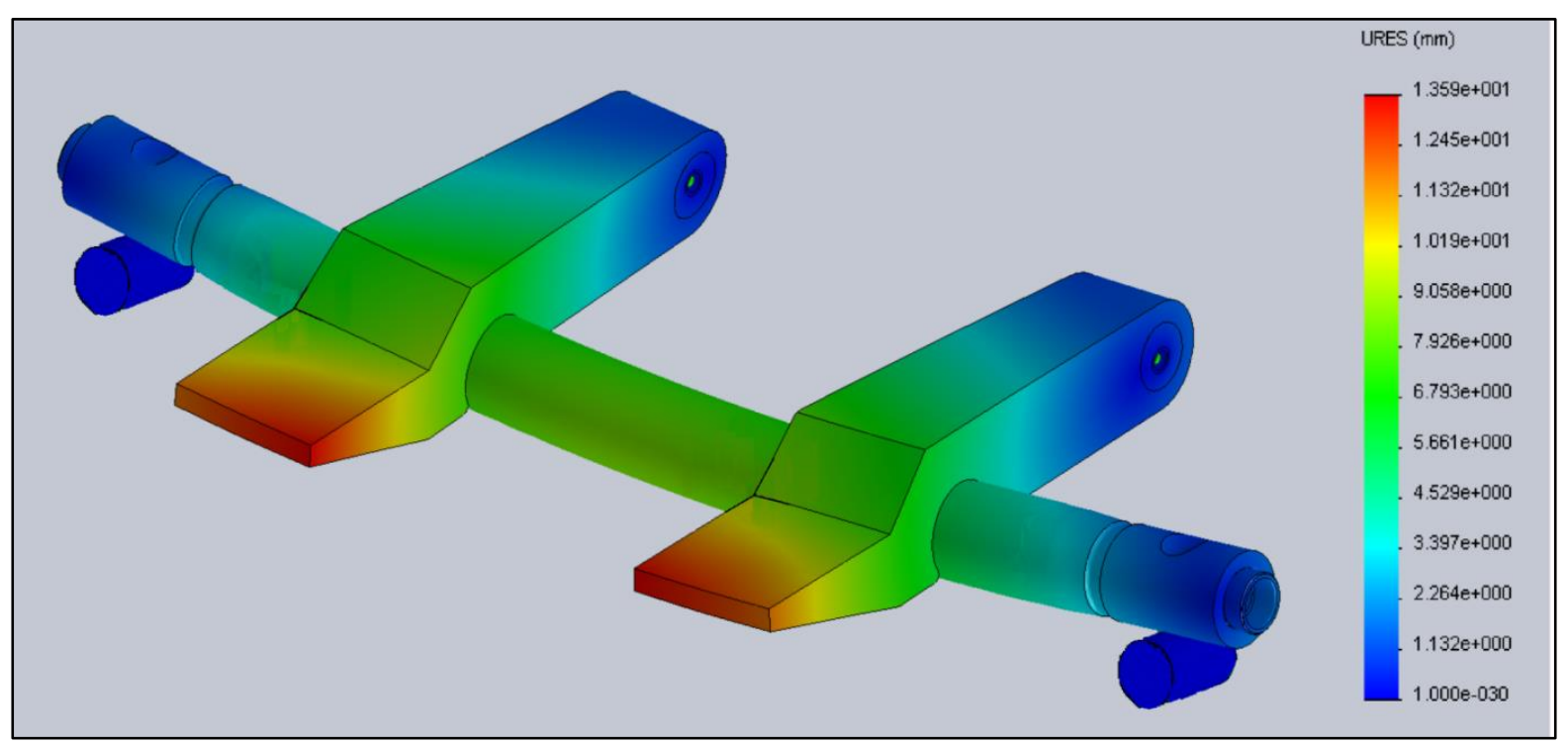

Figura 12 - Simulação dos deslocamentos, escala de distorção de 10 vezes 


\subsection{Instrumentação dos eixos:}

Com base nos esforços encontrados nas simulações, foram definidos 12 pontos de monitoração da deformação. Cada eixo foi instrumentado com 12 extensômetros (strain gages), conforme Figura 13.

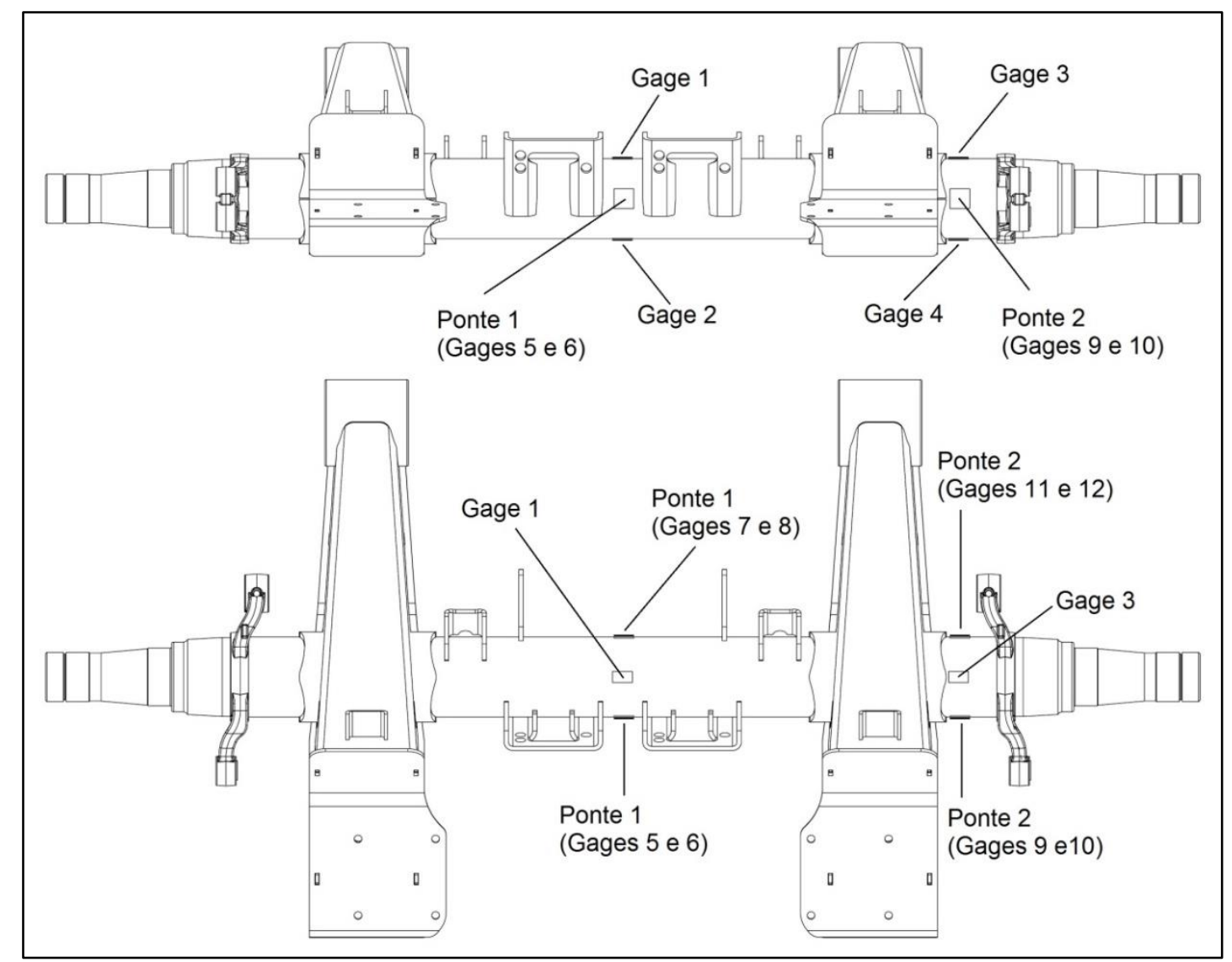

Figura 13 - Localização dos extensômetros (strain gages)

A seguir são apresentadas a identificação e os esforços medidos pelos gages.

Gages 1 e 2: Gages uniaxiais colados no centro do eixo para leitura dos esforços de flexão, gage 1 na parte superior e o gage 2 na inferior. Leituras individuais em $1 / 4 \mathrm{de}$ ponte.

Gages 3 e 4: Gages uniaxiais colados em uma das pontas para leitura dos esforços de flexão, gage 3 na parte superior e gage 4 na inferior. Leituras individuais em $1 / 4 \mathrm{de}$ ponte.

Gages 5, 6, 7 e 8: Duas rosetas de $90^{\circ}$ coladas no meio e na linha de centro a $45^{\circ}$ nos dois lados para leitura dos esforços de torção. Leitura em ponte completa, ponte 1 .

Gages 9, 10, 11 e 12: Duas rosetas de $90^{\circ}$ coladas na ponta e na linha de centro a $45^{\circ}$ nos dois lados para leitura dos esforços de torção. Leitura em ponte completa, ponte 2

As Figuras 14 e 15 mostram a instrumentação dos 2 eixos. 

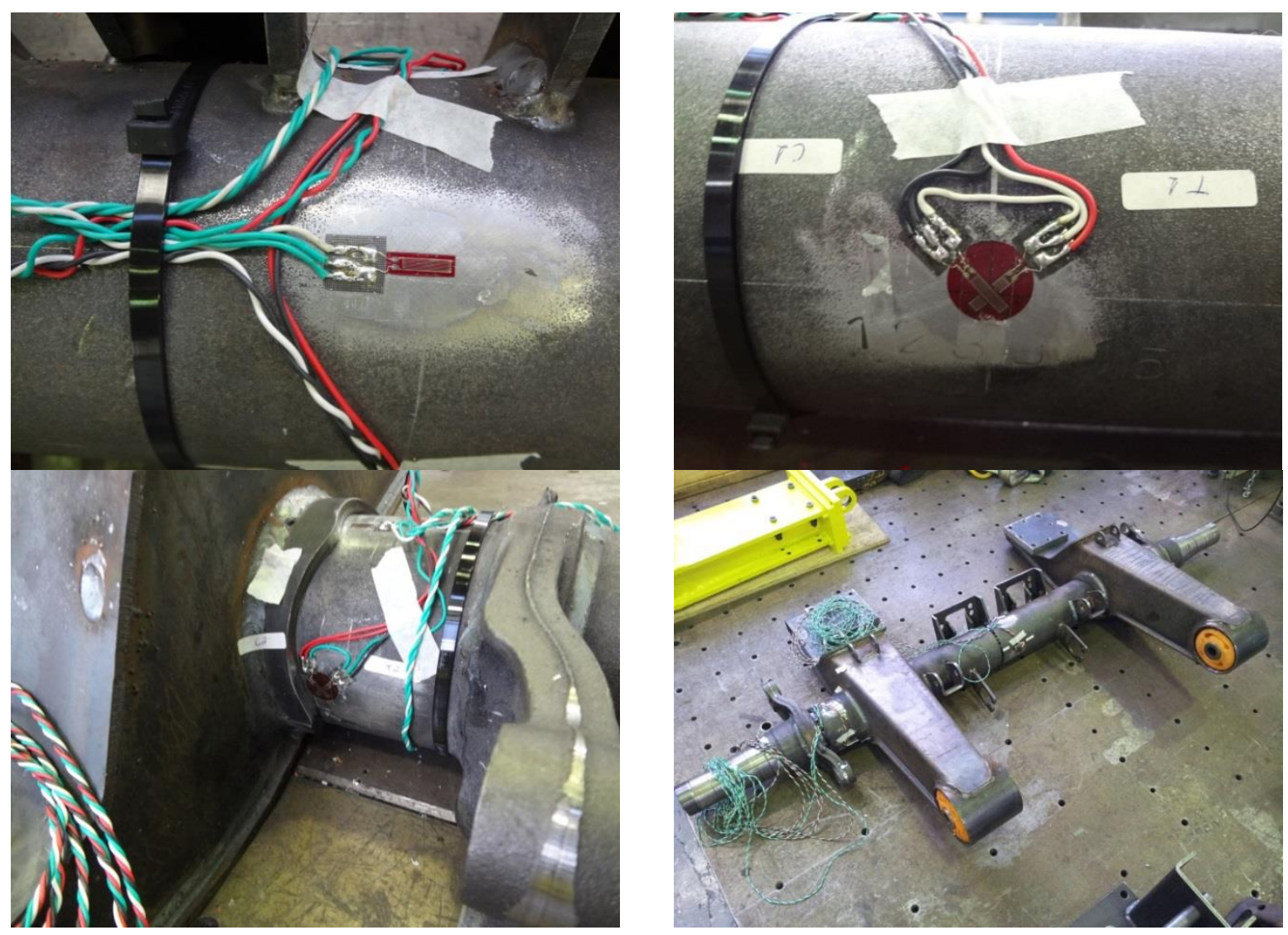

Figura 14- Instrumentação do eixo original
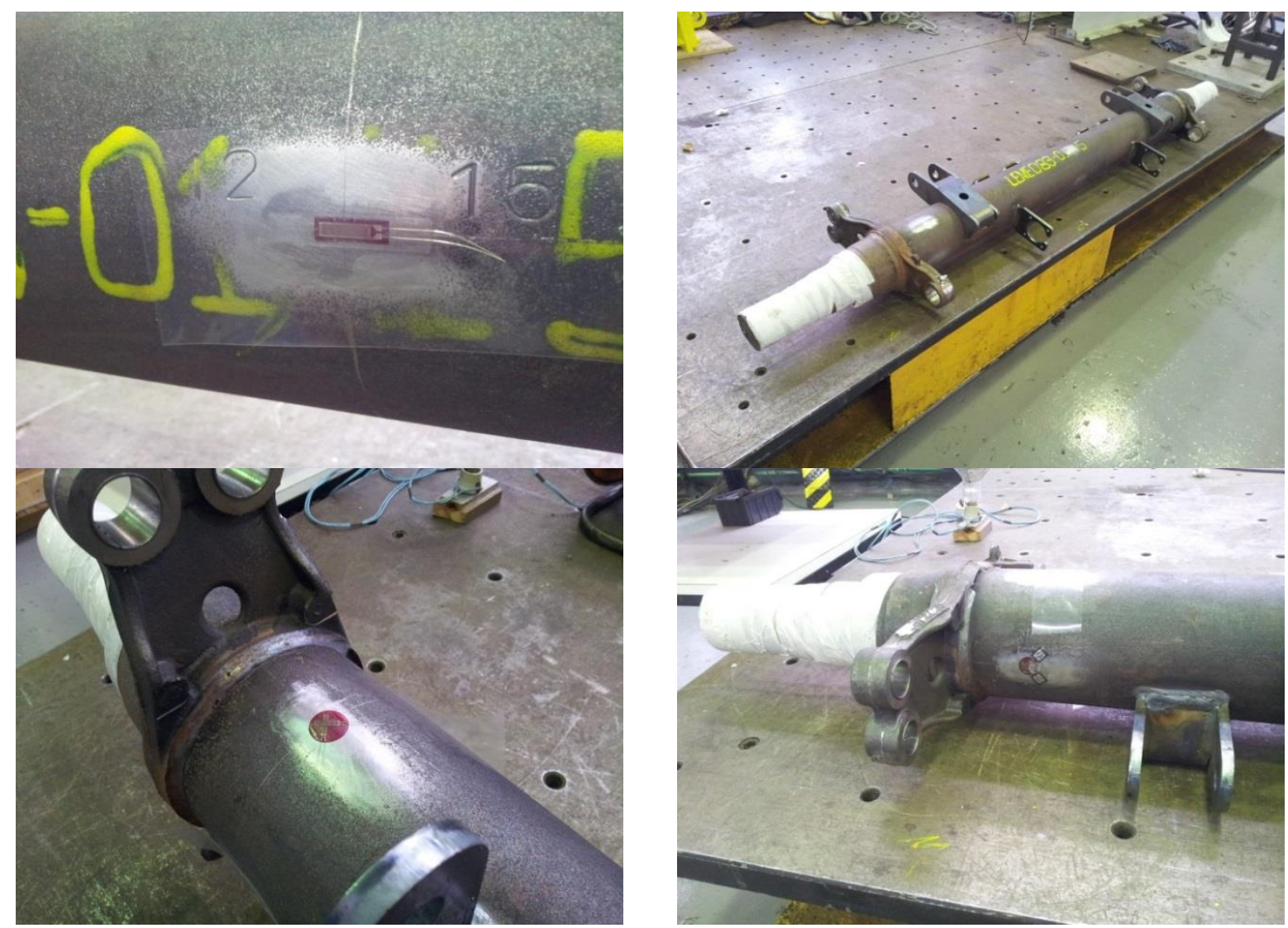

Figura 15 - Instrumentação do eixo modificado para suspensão com feixes de molas 


\section{ENSAIOS REALIZADOS}

Para avaliação dos esforços nos 2 eixos foram realizados ensaios estáticos, um para cada metodologia.

\subsection{Sistema de Aquisição de Dados}

Para ambos os ensaios as deformações dos gages foram monitoradas e registradas por um sistema de aquisição de dados, conforme Figura 16. Posteriormente foram gerados os gráficos das deformações e das forças aplicadas.

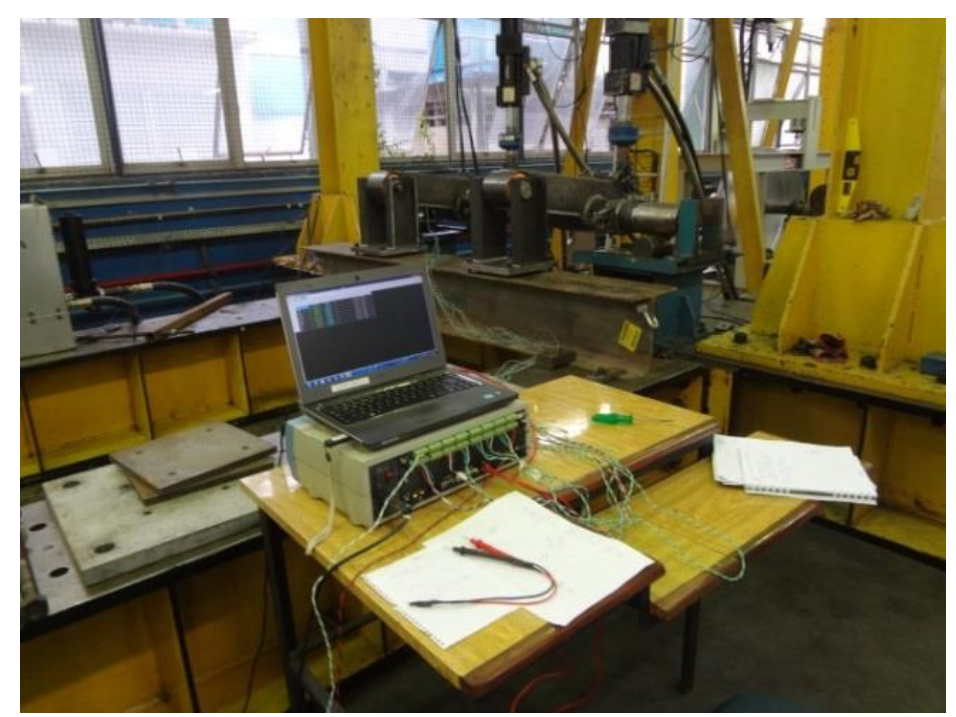

Figura 16 - Sistema de aquisição de dados

\subsection{Ensaio conforme a norma NBR 10961}

Após a montagem do eixo conforme o procedimento da norma NBR 10961 foram aplicados 23 patamares de força, de zero até duas vezes a carga nominal do eixo. A montagem do eixo na bancada é apresentada na Figura 17.
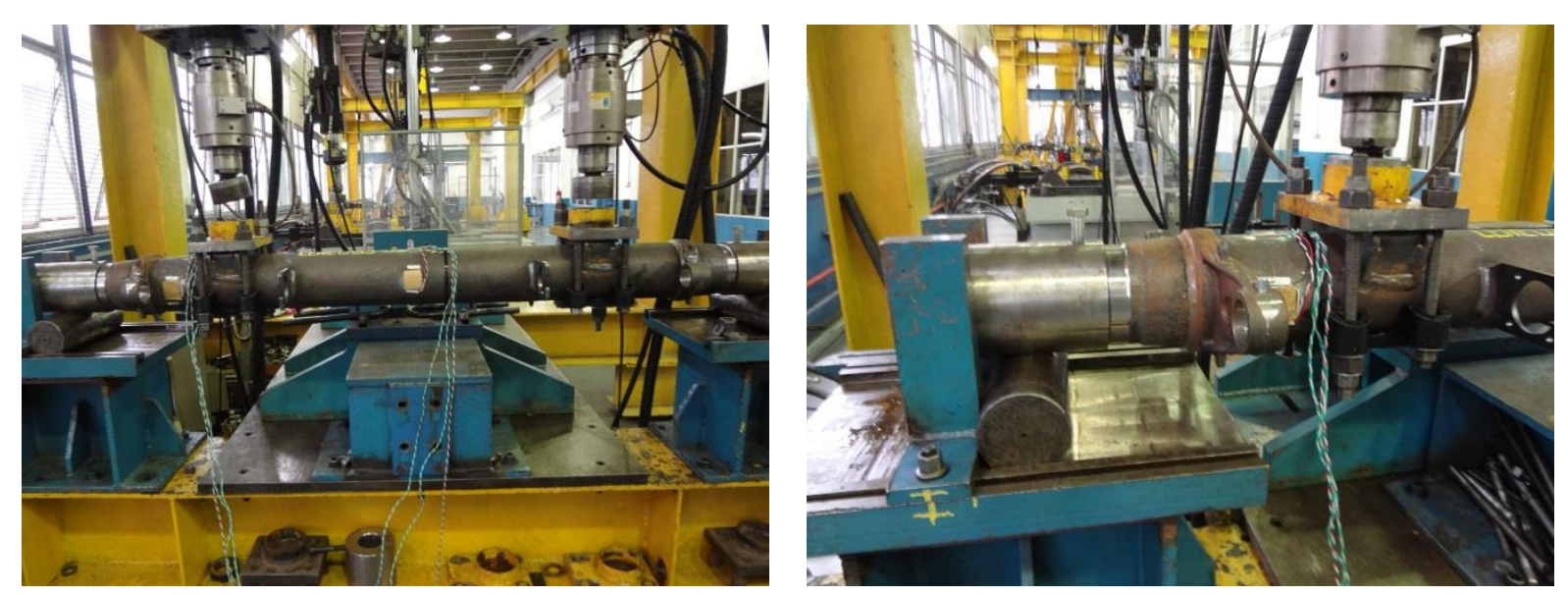

Figura 17- Montagem do ensaio conforme NBR 10961 


\subsection{Ensaio conforme montagem do eixo no veículo}

Para este ensaio foi seguido o mesmo procedimento da norma. Os valores das forças aplicadas nos braços de suspensão em cada lado do eixo foram proporcionais para que a reação nos apoios do eixo também fosse até duas vezes a carga nominal.
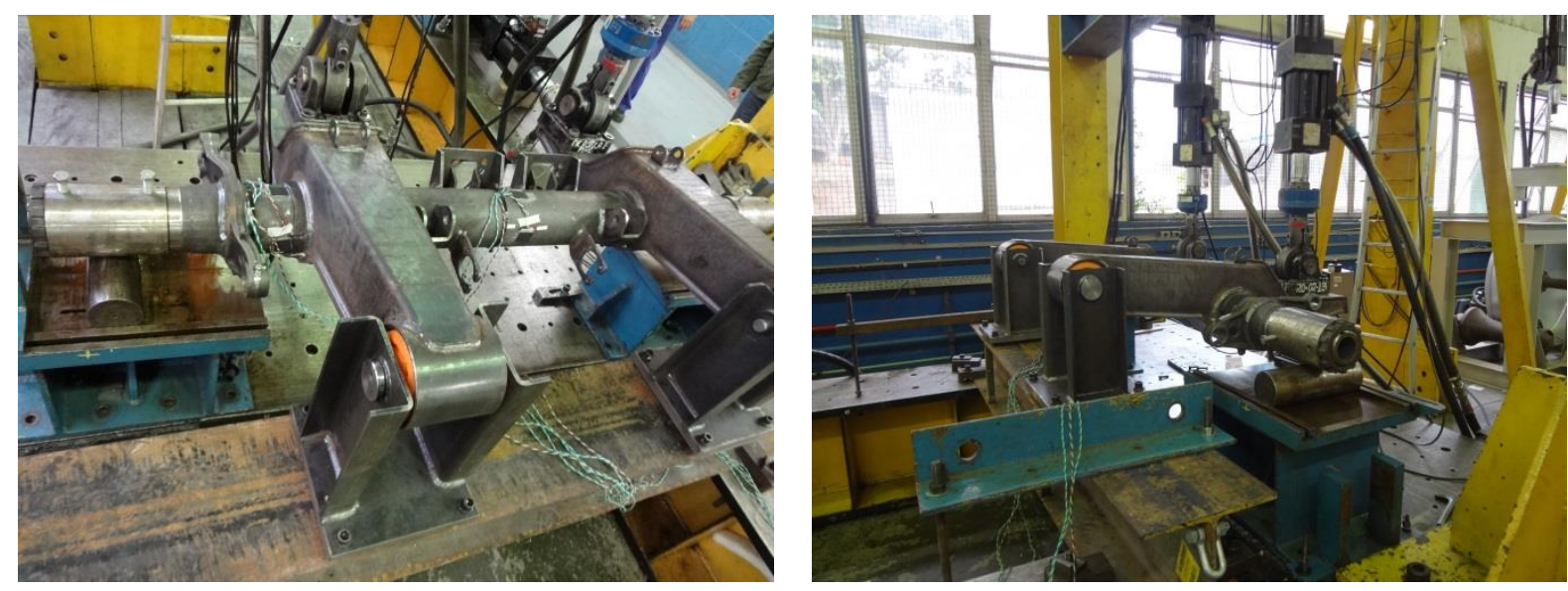

Figura 18- Montagem do ensaio do conforme aplicação real no veículo

\section{RESULTADOS}

Os resultados dos ensaios conforme a norma NBR 10961 e conforme a montagem real são apresentados nas Tabelas 1 e 2 e Figuras 19 e 20. Os valores negativos de deformação correspondem à esforço de compressão e os positivos à tração.

Tabela 1 - Valores da força aplicada e deformações obtidas - NBR 10961

\begin{tabular}{|c|c|c|c|c|c|c|c|}
\hline $\begin{array}{c}\text { Força em } \\
\text { cada } \\
\text { atuador } \\
(\mathrm{kN})\end{array}$ & $\begin{array}{c}\text { Força de } \\
\text { reação no eixo } \\
(\% \text { da carga } \\
\text { nominal) }\end{array}$ & $\begin{array}{c}\text { Ponte 1 } \\
(\mu \varepsilon)\end{array}$ & $\begin{array}{c}\text { Ponte 2 } \\
(\mu \varepsilon)\end{array}$ & $\begin{array}{c}\text { Gage 1 } \\
(\mu \varepsilon)\end{array}$ & $\begin{array}{c}\text { Gage 2 } \\
(\mu \varepsilon)\end{array}$ & $\begin{array}{c}\text { Gage 3 } \\
(\mu \varepsilon)\end{array}$ & $\begin{array}{c}\text { Gage 4 } \\
(\mu \varepsilon)\end{array}$ \\
\hline 0 & $0,0 \%$ & 2 & 9 & -2 & 3 & 2 & -1 \\
\hline 5,16 & $9,6 \%$ & -1 & 6 & -67 & 68 & -40 & 42 \\
\hline 10,32 & $19,1 \%$ & -5 & 2 & -131 & 132 & -81 & 85 \\
\hline 15,18 & $28,7 \%$ & -9 & -1 & -195 & 195 & -123 & 127 \\
\hline 20,64 & $38,2 \%$ & -11 & -3 & -257 & 255 & -163 & 168 \\
\hline 25,8 & $47,8 \%$ & -12 & -3 & -317 & 314 & -201 & 205 \\
\hline 30,96 & $57,3 \%$ & -10 & 0 & -378 & 372 & -240 & 243 \\
\hline 36,12 & $66,9 \%$ & -9 & 1 & -436 & 427 & -276 & 277 \\
\hline 41,28 & $76,4 \%$ & -9 & 2 & -494 & 482 & -312 & 312 \\
\hline 46,44 & $86,0 \%$ & -10 & 2 & -556 & 541 & -351 & 349 \\
\hline 51,60 & $95,5 \%$ & -10 & 2 & -606 & 587 & -382 & 378 \\
\hline 54,01 & $100,0 \%$ & -11 & 2 & -632 & 611 & -397 & 392 \\
\hline 56,76 & $105,1 \%$ & -11 & 2 & -661 & 638 & -415 & 408 \\
\hline 61,92 & $114,6 \%$ & -12 & 2 & -716 & 688 & -448 & 439 \\
\hline 67,08 & $124,2 \%$ & -13 & 2 & -761 & 738 & -481 & 469 \\
\hline 72,24 & $133,7 \%$ & -14 & 2 & -826 & 789 & -515 & 500 \\
\hline 77,40 & $143,3 \%$ & -14 & 4 & -883 & 841 & -551 & 534 \\
\hline 82,56 & $152,9 \%$ & -17 & 1 & -936 & 889 & -581 & 561 \\
\hline 87,72 & $162,4 \%$ & -19 & 0 & -991 & 939 & -615 & 592 \\
\hline 92,88 & $172,0 \%$ & -21 & -1 & -1047 & 991 & -650 & 625 \\
\hline 98,04 & $181,5 \%$ & -23 & -2 & -1103 & 1044 & -684 & 657 \\
\hline 103,2 & $191,1 \%$ & -23 & -2 & -1160 & 1098 & -719 & 691 \\
\hline 108,02 & $200,0 \%$ & -22 & -1 & -1214 & 1148 & -752 & 723 \\
\hline
\end{tabular}


Tabela 2 - Valores da força aplicada e deformações obtidas - Montagem real

\begin{tabular}{|c|c|c|c|c|c|c|c|}
\hline $\begin{array}{c}\text { Força em } \\
\text { cada } \\
\text { atuador } \\
(\mathrm{kN})\end{array}$ & $\begin{array}{l}\text { Força de } \\
\text { reação no } \\
\text { eixo (\% da } \\
\text { carga } \\
\text { nominal) }\end{array}$ & $\begin{array}{c}\text { Ponte } 1 \\
(\mu \varepsilon)\end{array}$ & $\begin{array}{c}\text { Ponte } 2 \\
(\mu \varepsilon)\end{array}$ & Gage $1(\mu \varepsilon)$ & Gage $2(\mu \varepsilon)$ & Gage $3(\mu \varepsilon)$ & Gage $4(\mu \varepsilon)$ \\
\hline 0 & $0,0 \%$ & 5 & 1 & 2 & 6 & -2 & 2 \\
\hline 3,0 & $9,6 \%$ & 19 & -3 & -61 & 71 & -41 & 34 \\
\hline 6,0 & $19,1 \%$ & 15 & -6 & -125 & 139 & -86 & 76 \\
\hline 9,0 & $28,7 \%$ & 12 & -9 & -191 & 208 & -132 & 117 \\
\hline 12,0 & $38,2 \%$ & 8 & -13 & -255 & 275 & -177 & 159 \\
\hline 15,0 & $47,8 \%$ & 7 & -16 & -320 & 344 & -223 & 200 \\
\hline 18,0 & $57,3 \%$ & 5 & -21 & -386 & 413 & -268 & 241 \\
\hline 21,0 & $66,9 \%$ & 3 & -25 & -451 & 481 & -314 & 281 \\
\hline 24,0 & $76,4 \%$ & 4 & -29 & -516 & 549 & -359 & 320 \\
\hline 27,0 & $86,0 \%$ & 9 & -34 & -581 & 617 & -403 & 359 \\
\hline 30,0 & $95,5 \%$ & 18 & -39 & -645 & 686 & -447 & 396 \\
\hline 31,4 & $100,0 \%$ & 23 & -42 & -675 & 717 & -467 & 414 \\
\hline 33,0 & $105,1 \%$ & 29 & -45 & -710 & 754 & -490 & 434 \\
\hline 36,0 & $114,6 \%$ & 37 & -50 & -774 & 821 & -534 & 471 \\
\hline 39,0 & $124,2 \%$ & 44 & -55 & -839 & 890 & -578 & 510 \\
\hline 42,0 & $133,7 \%$ & 50 & -61 & -904 & 957 & -622 & 548 \\
\hline 45,0 & $143,3 \%$ & 54 & -66 & -968 & 1024 & -665 & 586 \\
\hline 48,0 & $152,9 \%$ & 58 & -72 & -1033 & 1092 & -709 & 624 \\
\hline 51,0 & $162,4 \%$ & 62 & -77 & -1098 & 1151 & -753 & 664 \\
\hline 54,0 & $172,0 \%$ & 64 & -81 & -1163 & 1229 & -798 & 703 \\
\hline 57,0 & $181,5 \%$ & 68 & -85 & -1229 & 1298 & -843 & 742 \\
\hline 60,0 & $191,1 \%$ & 71 & -90 & -1294 & 1367 & -888 & 782 \\
\hline 62,8 & $200,0 \%$ & 73 & -93 & -1355 & 1431 & -930 & 818 \\
\hline
\end{tabular}

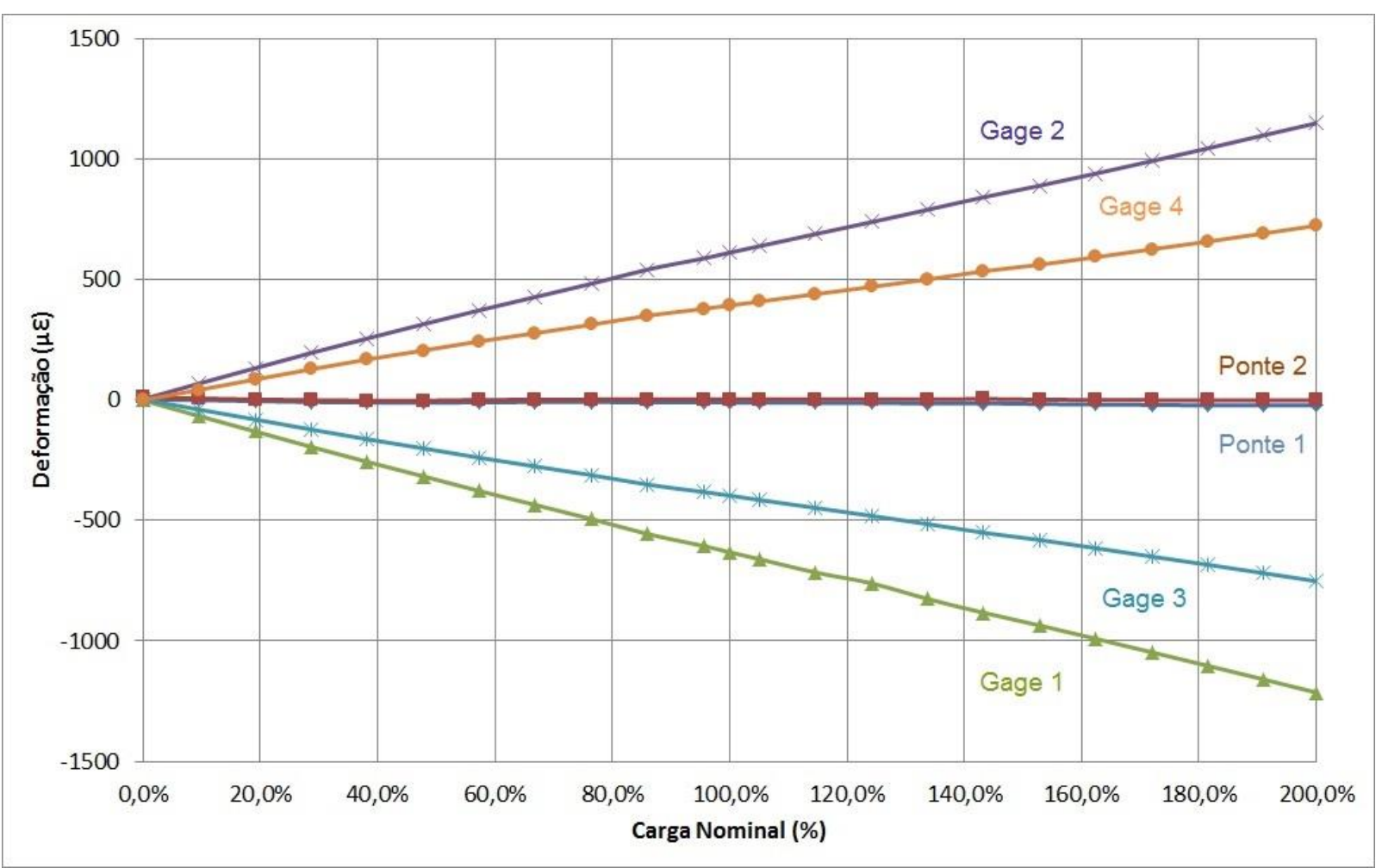

Figura 19 - Deformações obtidas em função da força de reação no eixo - NBR 10961 


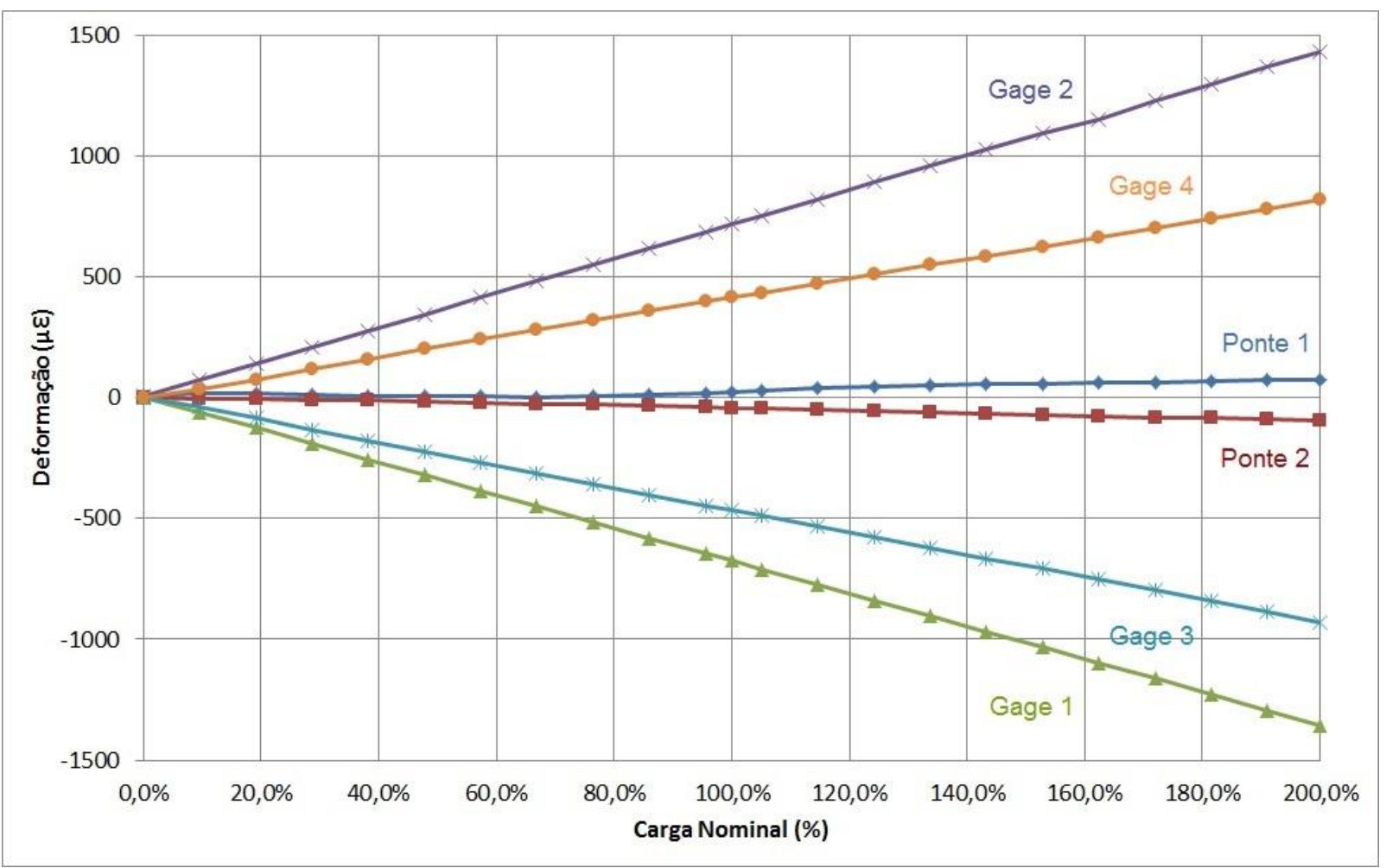

Figura 20 - Deformações obtidas em função da força de reação do eixo - Montagem real

\section{DISCUSSÕES}

Como a força máxima para o ensaio dinâmico conforme a Norma NBR 10961 é duas vezes a carga nominal do eixo, todas as análises dos ensaios estáticos realizados foram feitas para esta condição de $200 \%$ da força nominal.

Era esperada uma diferença entre os valores de deformações das simulações por elementos finitos e os valores medidos nos ensaios. Essa diferença foi confirmada e se deve principalmente: ao modelo tridimensional simplificado dos eixos; às imprecisões dos pontos de instrumentação; as imprecisões da fabricação do próprio eixo; e aos erros de montagem do ensaio. Para efeitos de comparação foram avaliados os valores dos 4 gages uniaxiais para as duas metodologias; as Figuras 21 e 22 apresentam os valores de deformações obtidos nas simulações.

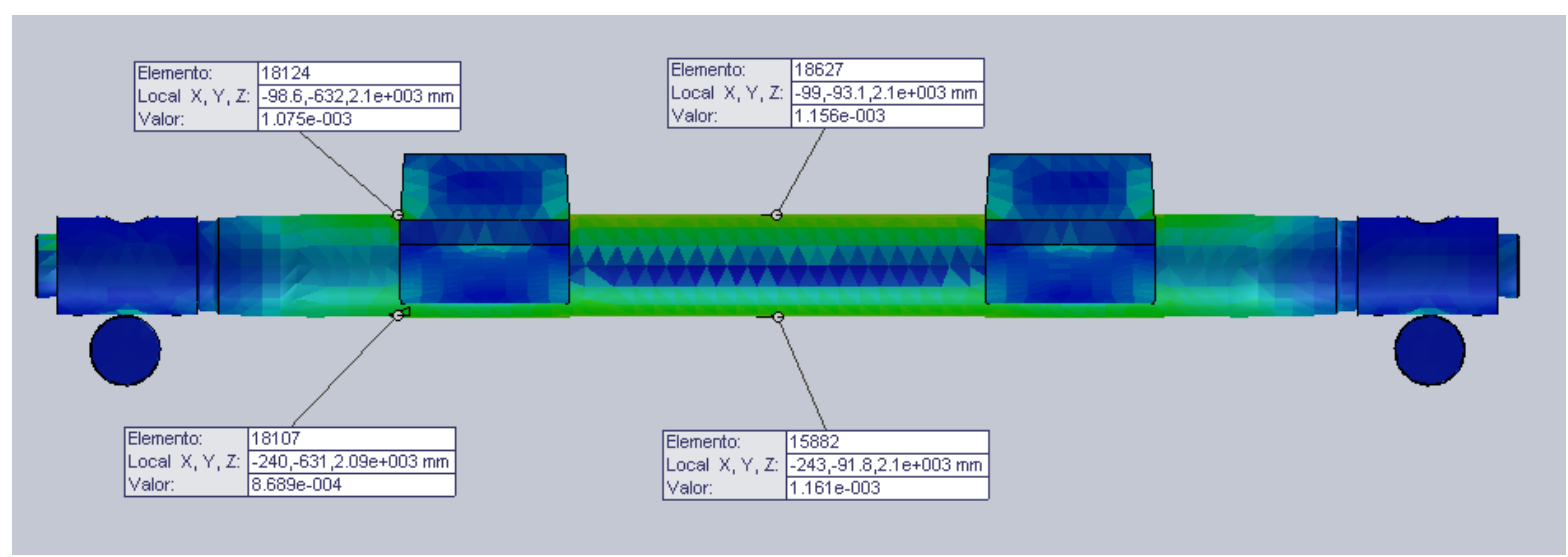

Figura 21 - Simulação conforme a Norma NBR10961 


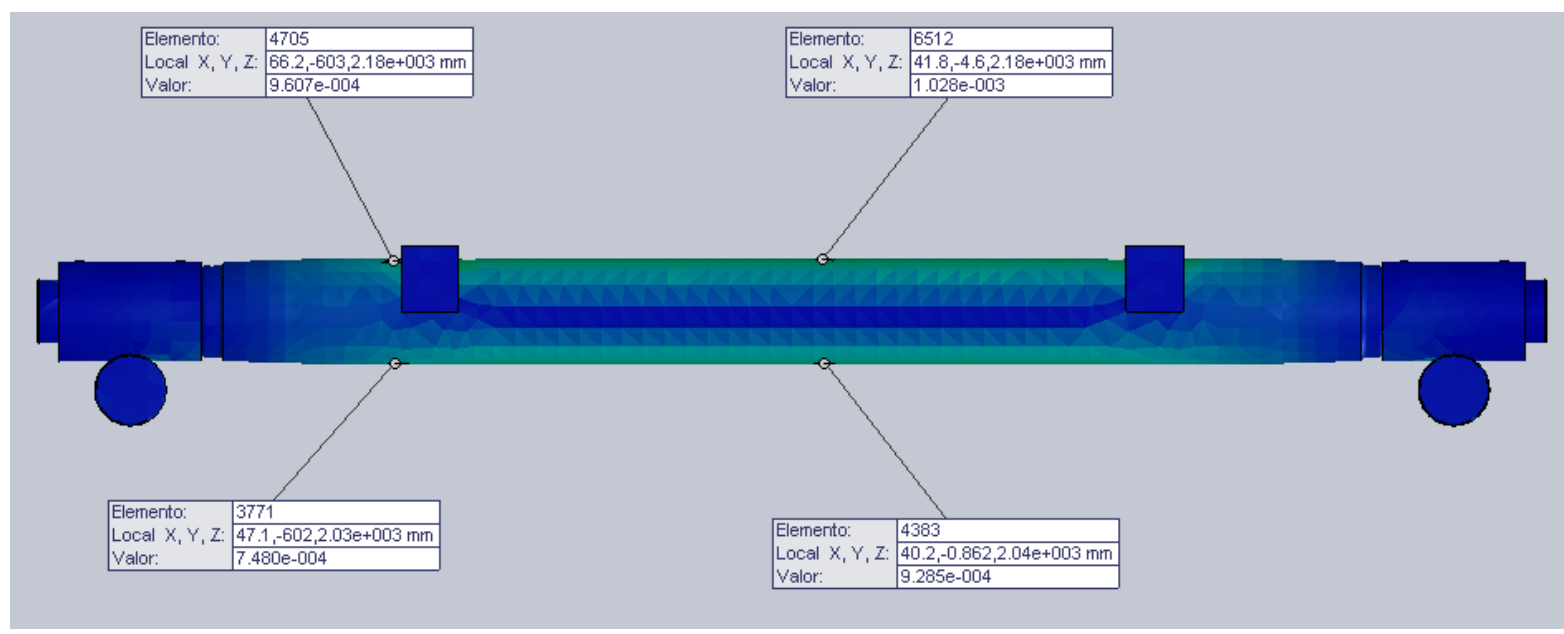

Figura 22 - Simulação conforme a nova metodologia

A Tabela 3 apresenta os valores de deformações medidos e simulados, para as duas metodologias, para força de reação no eixo de $200 \%$ da carga nominal. A Tabela 4 apresenta a relação em porcentagem entre os valores medidos e simulados.

Tabela 3 - Valores de deformação medidos e simulados - 200\% da força nominal

\begin{tabular}{|c|c|c|c|c|c|}
\hline $\begin{array}{c}\text { Metodologi } \\
\text { a }\end{array}$ & Valores & $\begin{array}{c}\text { Gage 1 } \\
(\mu \varepsilon)\end{array}$ & $\begin{array}{c}\text { Gage 2 } \\
(\mu \varepsilon)\end{array}$ & $\begin{array}{c}\text { Gage 3 } \\
(\mu \varepsilon)\end{array}$ & $\begin{array}{c}\text { Gage 4 } \\
(\mu \varepsilon)\end{array}$ \\
\hline \multirow{2}{*}{ NBR 10961 } & Medidos & -1214 & 1148 & -752 & 723 \\
\cline { 2 - 6 } & Simulados & -1028 & 928 & -960 & 748 \\
\hline $\begin{array}{c}\text { Montagem } \\
\text { real }\end{array}$ & Medidos & -1355 & 1431 & -930 & 818 \\
\cline { 2 - 6 } & Simulados & -1156 & 1161 & -1075 & 868 \\
\hline
\end{tabular}

Tabela 4 - Relação entre valores de deformação medidos e simulados - $200 \%$ da força nominal

\begin{tabular}{|c|c|c|c|c|c|}
\hline Metodologia & Valores & Gage 1 & Gage 2 & Gage 3 & Gage 4 \\
\hline NBR 10961 & Medidos/simulados & $+18 \%$ & $+24 \%$ & $-22 \%$ & $-3 \%$ \\
\hline Montagem real & Medidos/simulados & $+17 \%$ & $+23 \%$ & $-13 \%$ & $-6 \%$ \\
\hline
\end{tabular}

Conforme a Tabela 4 as maiores diferenças de deformações entre os valores medidos e simulados para o ensaio conforma a NBR 10961 foi de 24\% e para o ensaio conforme a nova metodologia foi de $23 \%$.

A Tabela 5 apresenta a relação em porcentagem entre os valores de deformações da nova metodologia e os valores conforme a norma NBR 10961 para 200\% da força nominal. São apresentados os valores das simulações e os medidos nos ensaios. Observa-se que tanto na simulação quanto nos ensaios os valores encontrados para o ensaio conforme a aplicação real foram até 25\% maiores que os valores conforme a norma NBR10961. Nas Figuras 19 e 20 pode-se observar que há uma tendência de aumento desta relação com o aumento da força de reação no eixo.

Tabela 5 - Relação entre as 2 metodologias para $200 \%$ da força nominal

\begin{tabular}{|c|c|c|c|c|}
\hline Montagem real /NBR10961 & Gage 1 & Gage 2 & Gage 3 & Gage 4 \\
\hline Valores simulados & $+12 \%$ & $+25 \%$ & $+12 \%$ & $+16 \%$ \\
\hline Valores medidos & $+12 \%$ & $+25 \%$ & $+24 \%$ & $+13 \%$ \\
\hline
\end{tabular}


Os gages 5, 6, 7 e 8 que formam a ponte 1 e os gages 9, 10, 11 e 12 que formam a ponte 2 foram considerados para avaliar possíveis esforços de torção, principalmente na montagem da nova metodologia.

O ensaio conforme a norma NBR 10961, não deveria apresentar qualquer efeito de torção no eixo, exceto pelas imprecisões de fabricação do eixo e da própria instrumentação e de desalinhamentos inerentes ao próprio ensaio. Para $200 \%$ da força nominal os valores encontrados para ambas as pontes ficaram praticamente próximos de zero, conforme a Tabela 1.

No ensaio conforme a nova metodologia o eixo apresentou uma pequena torção tanto no centro (ponte 1) quanto na ponta (ponte 2), desde o inicio da aplicação da força até $200 \%$ da força nominal, conforme Tabela 2. As buchas poliméricas montadas no ponto fixo dos braços da suspensão permitem liberdade para pequenos movimentos em todas as direções. No ensaio foi constatado um movimento da bucha de aço montada na ponta do eixo em relação ao rolete de apoio, considerando a força de reação nesta ponta e o coeficiente de atrito entre os pontos (aço/aço) pode se afirmar que foi aplicado um certo torque na ponta do eixo.

O estudo das torções tanto na simulação quanto nos ensaios não foram realizados nesta $1^{\mathrm{a}}$ fase do desenvolvimento da nova metodologia. Essa análise assim como outras serão realizadas numa $2^{\mathrm{a}}$ fase do trabalho.

\section{CONCLUSÕES}

Para a força de reação de 2 vezes a nominal no eixo os esforços de flexão foram até $25 \%$ maiores na metodologia nova em relação á metodologia da norma NBR 10961. Na nova metodologia também ocorreram pequenos esforços de torção no eixo os quais não ocorreram nos ensaios conforme a Norma NBR 10961. Portanto o eixo quando ensaiado conforme a norma NBR 10961 está sendo menos exigido estruturalmente.

É importante também citar que quando se ensaia um eixo para ser utilizado em suspensões pneumáticas em condições de uso em suspensão com feixes de molas, não se ensaia um dos elementos principais do sistema de suspensão pneumática, que é o braço de suspensão, além de não avaliar as regiões do eixo e do próprio braço onde é feita a soldagem entre ambos.

\section{AGRADECIMENTOS}

Os autores agradecem o apoio da equipe técnica do Laboratório de Equipamentos Mecânicos e Estruturas - LEME do IPT, especialmente: Jorge Antonio de Lima, Cleiton Ernandes Alves da Silva, Leandro Duarte da Costa e Carlos Eduardo Lourenço na simulação e realização dos ensaios; Edson Hiroki Amano e José Trevelin na instrumentação dos eixos e aquisição de dados. 


\section{REFERÊNCIAS}

[1] ABNT NBR 10961, 2009, Implementos Rodoviários - Caminhão, caminhão-trator, ônibus, reboque e semirreboque - Eixo veicular - Requisitos e métodos de ensaio, Associação Brasileira de Normas Técnicas, Rio de Janeiro, Brasil.

[2] FIRAT, Mehmet. A computer simulation of four-point bending fatigue of a rear axle assembly. Engineering Failure Analysis, University of Sakarya, Dept. of Mech.

Engineering, 54187 Adapazari, Turkey, v. 18, p. 2137-2148, 2011.

[3] WANG, X.; XU, W.; HUANG, Y.; ZHONG, M.; FAN, H. Simulation of the vertical bending fatigue test of a five-link rear axle housing. International Journal of Automotive Technology, State Key Laboratory of Automotive Safety And Energy, Dept. of Automotive Engineering, Tsinghua University, Beijing 100084, China, v. 13, No. 6, p. 923-932, 2012.

[4] LEE, Yuejun E. Correlation and Simulation Process Improvement for Automotive Axle. SAE Technical Paper (2007-01-1205), 2007. 